\title{
TI COMO PLATAFORMA LOGÍSTICA DO EAD EM UMA INSTITUIÇÃO DE ENSINO SUPERIOR
}

Fernando Carlos Rodrigues

Discente do Curso de Pós-Graduação em Administração da TI da UNOESTE, Presidente Prudente, SP. e-mail: ferik09@yahoo.com.br

\begin{abstract}
RESUMO
$\mathrm{Na}$ atual conjectura socioeconômica nacional é nítida a carência de profissionais qualificados, principalmente os de nível superior, contudo o modelo de ensino a distância tem se mostrado como uma potencial e promissora porta de escape desta circunstância, entretanto somente o investimento financeiro nesta área não basta, é necessária adoção de uma rotina de aprimoramento dos processos para atingir os objetivos maiores. Desta forma, este artigo tem por finalidade apresentar uma breve visão sobre a empregabilidade dos conceitos relacionados à Logística e a Gerenciamento da Cadeia de Suprimentos, no que diz respeito ao aperfeiçoamento da gestão da infraestrutura TI na modalidade de Ensino a Distância em uma Instituição de Ensino Superior.
\end{abstract}

Palavras-chave: TI, logística, EAD, gestão, ensino superior.

\section{IT AS A LOGISTICS PLATFORM DISTANCE EDUCATION IN UNIVERSITY}

\begin{abstract}
In the current national socioeconomic conjecture is a clear shortage of qualified professionals, especially at tertiary level, however the model of distance learning has been shown to be a potential and promising exhaust port this circumstance, however only the financial investment in this area is not enough, and required adoption of a routine process improvement to achieve the larger goals. Thus, this article aims to present a brief overview on the employability of concepts related to Logistics and Supply Chain Management, with regard to improving the management of IT infrastructure in the form of the Distance Learning in a University.

Keywords: IT, logistics, distance education, management, universities.
\end{abstract}




\section{INTRODUÇÃO}

O Brasil passa por um momento de importantes transformações no seu cenário interno, onde que fatores críticos para desenvolvimento ressurgem como impedimentos para o crescimento sustentável, são velhas mazelas conhecidas pela nação correspondentes a gargalos que emperram o país de conseguir atingir novas posições socioeconômicas no âmbito mundial. Dos vários fatores que promovem a estagnação, os maiores ainda são a defasagem da infraestrutura, a legislação arcaica, a burocracia e a falta de mão de obra qualificada. No entanto, não desprezando os outros gargalos que são importantíssimos, mas o objetivo deste trabalho é o foco na questão logística para a formação de mão de obra qualificada, mais propriamente dito o uso da infraestrutura de $\mathrm{TI}$ como plataforma logística no sistema de Ensino a Distância (EAD) para o Ensino Superior.

Contudo é necessário entender as partes que compõe o todo desta temática, como já mencionado a falta de mão de obra qualificada torna-se um inevitável embargo ao crescimento nacional, tendo em vista desta problemática algumas soluções têm surgido para amenizar a carência de profissionais no mercado interno, e neste contexto a EAD tem-se apresentado como uma desafiadora área para a formação de mão de obra qualificada, constituída pelo aspecto pedagógico mais o de infraestrutura, sua regulamentação está descrita conforme o DECRETO № 5.622 (2005), contudo essa lei sofreu algumas alterações no seu dispositivo, onde que os seus artigos 10,12, 14, 15 e 25 passaram a ser conduzidos pelo DECRETO № 6.303 (2007) que dispõe sobre o exercício das funções de regulação, supervisão e avaliação de instituições de educação superior e cursos superiores de graduação e sequenciais no sistema federal de ensino, porém no âmbito de conhecer o conceito legal de Educação a Distância utilizaremos o texto do artigo primeiro do DECRETO № 5.622 (2005), que diz:

Art. 1Para os fins deste Decreto, caracteriza-se a educação a distância como modalidade educacional na qual a mediação didáticopedagógica nos processos de ensino e aprendizagem ocorre com a utilização de meios e tecnologias de informação e comunicação, com estudantes e professores desenvolvendo atividades educativas em lugares ou tempos diversos.

Nota-se já a partir da referência citada a evolução do conceito de educação ante a prática tradicional, com a inserção das tecnologias de informação no cotidiano e principalmente depois do inicio do uso da internet através da web, a sociedade tem sofrido constantes transformações em suas relações, e segundo Gates (1995, p. 231), no seu livro "A Estrada do Futuro", menciona o rompimento deste paradigma através da tecnologia, iniciando o capítulo sobre "educação" da seguinte forma:

Os grandes educadores
sempre souberam que
aprender não é algo que você
faz apenas na sala de aula ou
sob a supervisão de
professores. Hoje, é por vezes
difícil para quem quer
satisfazer sua curiosidade ou
resolver suas dúvidas
encontrar a informação
apropriada. A estrada dará a
todos nós acesso a
informações aparentemente
ilimitadas, a qualquer lugar
que queiramos. É uma
perspectiva animadora porque
colocar essa tecnologia a
serviço da educação resultará
em beneficio para toda a
sociedade.

Neste contexto e seguindo a evolução digital, o Brasil, segundo Moran (2007), passou de apenas usuário de modelos de EAD para 
desenvolvedor de novos projetos e programas complexos, e através do aprimoramento dos processos de implantação e gestão foi possível romper a barreira da desconfiança e da falta de credibilidade que pairava sobre as EADs, com a aceitação pelo mercado, esta simbiose entre tecnologia e educação tem se declarado como uma eficiente ferramenta de formação educacional.

Mas um dos pontos que demanda mais atenção neste tipo de negócio é a capacidade da Instituição de Ensino Superior (IES) conseguir ter a satisfatória eficiência na gestão dos processos envolvidos, e para tanto, a IES que desempenha este papel de forma hábil, rentável e com qualidade para o seu público alvo, consegue definir a sua posição e sobrevivência no mercado, uma das formas de entender como se obtém esta almejada prática é através da aquisição do conceito de Logística, conforme descrito por Carvalho (2002, p. 31):

Parte do Gerenciamento da Cadeia de Abastecimento que planeja, implementa e controla o fluxo e armazenamento eficiente e econômico de matérias-primas, materiais semi-acabados e produtos acabados, bem como as informações a eles relativas, desde o ponto de origem até o ponto de consumo, com o propósito de atender às exigências dos clientes.

Mais o conceito de infraestrutura de TI, segundo Weiss (2009, p. 21)

A infraestrutura de TI consiste nos componentes físicos e os sistemas necessários para viabilizar o desenvolvimento de cursos EAD utilizando a web. Os componentes físicos são os computadores, servidores, equipamentos de gravação de vídeos e áudios, entre outros componentes que serão utilizados para tornar possível a criação, armazenamento e difusão de conteúdos e cursos. Os sistemas são os programas de computador utilizados para criar, editar, gerenciar e disponibilizar os cursos.

Com a fusão destas definições de logística e infraestrutura de TI, mais associação das regras de negócio para educação à distância, consegue-se estabelecer um modelo de caminho para dar vida à plataforma dos processos EAD, o qual pode ser definido com sendo o conjunto de planejamento e gerenciamento eficiente do fluxo de informações, viabilizado através de uma infraestrutura de recursos tecnológicos aplicados na autoaprendizagem, onde que, todas as operações e processos submetem-se à regulamentação do um modelo didático pedagógico especifico.

\section{METODOLOGIA}

Esse artigo foi fruto de uma pesquisa bibliográfica, o qual foi apresentado à disciplina de Logística Aplicada a TI que faz parte do curso de Especialização em Administração da Tecnologia da Informação, cuja Instituição é a Universidade do Oeste Paulista (UNOESTE), o seu escopo teve por intuito refletir como que a TI associada às boas práticas de Logística e Cadeias de Suprimentos podem ajudar a implementar o processo de educação a distância. Para a confecção desta pesquisa foi realizado o levantamento dos materiais bibliográficos de diversas fontes, tais como: livros da rede de Bibliotecas da UNOESTE, artigos, teses, monografias, leis, periódicos, sites, e as notas de aula no curso de Especialização, sendo que após esse levantamento houve a compilação dos materiais cujos temas alinhavam com o objetivo geral do trabalho, e através da exaustiva leitura destes materiais foi realizada a sintetização de todo o conglomerado de informações, no qual resultou neste artigo. 


\section{A TI COMO SUPORTE LOGÍSTICO NA EAD}

A infraestrutura de $\mathrm{TI}$ composta pelos componentes físicos e os sistemas necessários, serve como alicerce logístico para os processos $E A D$, essa têm por objetivo a disponibilização, manutenção, e gestão dos recursos prestados aos usuários, sendo que o sistema computacional que faz a interface entre o aluno e o tutor ocupa um lugar vital neste conjunto, pois é através dele que se fará a interação entre as partes, bem como, a gestão logística do fluxo de informações . Portanto toda a infraestrutura de TI serve como suporte para o sistema, no qual este, no ramo da educação a distância pode ser designado como: AVA (Ambiente Virtual de Aprendizagem).

Segundo Almeida (2003):

Ambientes virtuais de
aprendizagem são sistemas
computacionais disponíveis na
internet, destinados ao suporte
de atividades mediadas pelas
tecnologias de informação e
comunicação. Permitem
integrar múltiplas mídias,
linguagens e recursos,
apresentar informações de
maneira organizada,
desenvolver interações entre
pessoas e objetos de
conhecimento, elaborar e
socializar produções tendo em
vista atingir determinados
objetivos.

Desta forma, o AVA sendo fundamental no processo de EAD, é dele que parte a criação, gerenciamento das disciplinas ou cursos, fornecendo um ambiente no qual os usuários poderão interagir com os conteúdos, com outros usuários e tutores. Por ter posição privilegiada dentro do contexto EAD o AVA pode contribuir para a criação diferencial competitivo para a Instituição, pois é através da gestão sistemática e eficaz do fluxo de informações é possível a implantação do gerenciamento logístico, e segundo este fator, Christopher (2009, p. 14) descreve:
O gerenciamento logístico, do ponto de vista sistêmico, é o meio pelo qual as necessidades dos clientes são satisfeitas mediante a coordenação dos fluxos de materiais e de informações que se estendem do mercado, passando pela empresa e suas operações, até os fornecedores.

Dentro deste esquema logístico entre fornecedor e cliente, o sistema é capaz realizar suas operações por meio de canais, no AVA, são dois os canais de interação, o canal de interação síncrona, que acontece em tempo real entre as partes envolvidas, podendo ser dividida em webaulas, chats, videoconferência, e o canal de interação assíncrona que ocorre quando não há simultaneidade, isto é, possuindo intervalos de tempo mais longos, nesta interação as possibilidades de atividades podem ser: a hospedagem de material didático da disciplina ou do curso, vídeo aulas, portfólio, diário de bordo, calendário, fóruns, blogs, questionários, correio eletrônico, narrações, imagens, textos complementares, vídeos, games-learning (jogos educativos), provas, espaço para upload de arquivos e trabalhos orientados.

\section{Essa exploração das plataformas} multiformes dentro do AVA tem por finalidade contemplar uma maior capacidade de assimilação e construção do conhecimento pelos indivíduos, principalmente dentro de grupos heterogêneos onde que a possibilidade da diversificação dos recursos poderá atingir as diferentes habilidades e competências do raciocínio humano, sobre esse aspecto Barros (2008, p. 39) diz que:

É consenso entre estudiosos da educação que a comunicação midiada desperta a atuação dos nossos sentidos de novas maneiras, daí advindo o poder da informação multimídia. Como o conteúdo em um CD- 
ROM ou em uma página multimídia na Internet apela para os sentidos da visão e da audição ao mesmo tempo, a carga informativa é significativamente maior. Com estes sentidos sendo solicitados simultaneamente, a informação é mais redundante, oferecendo um maior poder de assimilação e retenção. Além do que, amplia-se a atenção, já que os apelos sensoriais são multiplicados e comumente inesperados e surpreendentes.

Desta forma, a utilização da multimídia como recurso para este processo de ensino aprendizagem pode trazer inúmeras vantagens, tais como: tornar o aprendizado mais agradável e interessante, devido à possibilidade da inclusão de sons, fotos, imagens, animações, vídeo, entre outras mídias, com já citado anteriormente; tornar as aulas menos monótonas e despertar no aluno o interesse à investigação e à descoberta; com a ajuda dessas ferramentas, novas formas de se expressar os conceitos tornam-se viáveis, tais como, experiências virtuais. Um software em multimídia também pode ser elaborado para que 0 aluno "aprenda brincando". Isto se torna possível através da utilização de jogos educativos.

É importante ressaltar que, quanto mais diversificados e atraentes forem estes "canais logísticos" disponibilizados pelo sistema, maior será a oportunidade do aprendizado pelos usuários, consequentemente poderá ajudar a agregar diferencial competitivo para a Instituição.

\section{RESULTADOS E DISCUSSÃO}

\section{O Uso de Boas Práticas Aplicadas em Logística}

Não há como negar que ao passar do tempo a $\mathrm{TI}$ vem se tornando uma commodity (mercadoria), e os usuários estão mais exigentes, não só em relação à qualidade dos produtos, mas também quanto aos serviços, desta forma a diferença técnica entre os concorrentes nesta área é por muitas vezes mínima e quase imperceptível, portanto é aconselhável a criação de mecanismos que dê vantagem diferencial e consiga agregar valor aos produtos e serviços que serão entregues aos usuários. Para tal, a IES que almeja o destaque dentro do universo EAD poderá fazer uso do modelo de competição de cadeias de suprimento derivado da Logística, o qual este modelo é conhecido como princípios dos "4Rs": responsividade (responsiveness), confiabilidade (reliability), resilência (resilience) e relacionamentos (relationships), segundo Christopher (2009, p. 37) a inclusão destes princípios sugere a criação de um diferencial competitivo por meio da estratégia logística integrada, onde que as ações aconteceriam no âmbito tecnológico e organizacional da IES com foco central no usuário. Dentro desta dinâmica, os princípios dos "4Rs" poderiam ser entendidos de tal maneira:

Responsividade - Atenção oferecida pela Instituição através dos recursos do AVA e organizacionais a fim de responder as expectativas dos seus clientes, ou seja, a disponibilização de soluções cada vez mais flexíveis, rápidas, e customizadas. A forma de empreender essas soluções seria por meio de atualizações constantes na plataforma tecnológica e capacitações periódicas dos recursos humanos, onde que usuário final seria o principal privilegiado devido ao menor tempo de espera possível em face de suas necessidades, esse princípio tem por foco tornar todo o processo mais ágil.

Confiabilidade - capacidade da IES de atender a promessa de fornecimento dos serviços EAD com qualidade e segurança através da reelaboração dos processos que causam impacto no seu desempenho. Para tanto, a gestão IES 
poderia viabilizar este princípio por meio da implantação de um canal, o qual teria a clara função de visibilidade de ponta a ponta de todo processo. Para ajudar na criação deste canal a IES faria uso de ferramentas da TI como o CRM (Customer Relationship Management Gerenciamento do Relacionamento com Cliente) as quais propiciariam aos gestores condições mais favoráveis de analisar todo o processo, e conseqüentemente pontuar as ações através da uma perspectiva sistêmica dentro da organização. Outro ponto que passível de implementação dentro deste principio da confiabilidade, são os canais de feedback (realimentação) aos usuários, mesmo sendo estes, dentro ou fora do AVA, a sua implementação teria por propósito estabelecer e fortificar para o usuário o conceito de processo transparente e confiável entre ele e a Instituição, este princípio tem por objetivo de fortalecer o vinculo institucional de confiança com o cliente.

A resiliência - É a capacidade da infraestrutura da IES, tecnológica e humana, de suportar a volatilidade do mercado. O primeiro ponto deste princípio seria o desenvolvimento de uma política de autoconhecimento dentro da instituição, na qual por meio de práticas constantes de levantamentos e análises dos seus pontos fortes, fracos, e fatores críticos para o sucesso seria possível fazer o mapeamento institucional de suas principais potencialidades e fragilidades, e posteriormente caracterização e dimensionalização das vulnerabilidades organizacionais. Em segundo lugar, ao fazer uso deste princípio a Instituição poderia desenvolver a habilidade de evolução tecnológica e social em consoante às mudanças dos cenários onde está inserida, aqui vale ressaltar a importância desta habilidade nos dias atuais, principalmente dentro da esfera tecnológica onde que as necessidades de atualizações são constantes e demandam respostas rápidas às variações, a organização que não conseguir absorver tais mudanças poderá correr 0 risco de estagnação e conseqüente perca de diferencial competitivo, neste princípio o objetivo é capacidade adaptativa da Instituição em face as turbulências do mercado.

Relacionamentos - Em frente a esse principio também há dois aspectos a serem focados, o primeiro seria a interação entre o prestador de serviço (a IES), e o cliente (o usuário do AVA), nesta relação segundo Christopher (2009, p. 37), deve haver uma relação de "ganhaganha", isto é quanto maior for a integração de processos entre fornecedor e cliente maior deverá ser a reciprocidade e confiança entre eles. Para estimular implantação deste aspecto, a inclusão de práticas já mencionadas como a do CRM e do feedback ajudaria a estreitar os laços de confiança entre as partes promovendo o lucro para ambos.

Em segundo lugar, levando em consideração o aspecto pedagógico do AVA, o principio de relacionamentos faria parte da construção da capacidade de sincronismo entre os recursos do AVA e os recursos de outras redes e dispositivos, para tal variável, a IES que conseguisse trabalhar de forma efetiva desenvolvendo a integração de sua plataforma com os demais TICs (Tecnologias de Informação e Comunicação) poderia adicionar diferencial competitivo aos seus serviços através da construção de uma teia do saber dinâmica, a qual essa "rede de relacionamentos" promoveria a interação dos mais diversos gêneros através da capacidade de absorver as experiências e dividir os conhecimentos interligados, neste princípio os objetivos são o fortalecimento do vínculo de proximidade e a capacidade de desenvolver conhecimento mútuo. Assim desta forma ao aplicar a teoria dos princípios dos "4Rs" no EAD Instituição poderia se beneficiar com a inclusão 
de práticas sustentáveis e atualização constante em face das necessidades de seus clientes.

Outro modelo possível de ser usado na gestão do EAD é o benchmarking (análise comparativa) - é uma técnica que consiste em comparar o desempenho de algum processo, prática de gestão ou produto da organização com o de um processo, prática ou produto similar que esteja sendo executado de forma mais eficiente, na própria ou em outra organização, segundo (RELATÓRIO, 2005). No caso da TI como plataforma logística da EAD o uso do benchmarking é muito propício, pois pelo intermédio deste dispositivo a IES poderá conseguir promover o levantamento e a tabulação dos indicadores de desempenho e conseqüentemente um melhor direcionamento dos esforços para a gestão eficiente em todo processo. A comparação de suas operações na cadeia de suprimentos em face há dos líderes de mercado, ajudará estipular uma métrica coerente e responsável para avaliação, implementação e aprendizagem dos processos logísticos internos ou externos, evidenciando o velho clichê "O que pode ser medido, pode ser gerido".

Para a aplicação desta técnica segundo Weiss (2009, p. 45), pode-se usar parametrização para subdividir a análise, com os seguintes itens comparadores:

a) Empresa: contextualizar o objetivo da empresa e do AVA;

b) Site: a página web em que se encontra 0 sistema.

c) AVA: qual o AVA utilizado pela empresa, verificando se ela utilizou um pacote já existente ou criou um sistema próprio.

d) Recursos tecnológicos disponíveis: quais os recursos que a web oferece atualmente foram utilizados (vídeos, áudios, animações, entre outros).

e) Tutores: O quadro de tutores conforme sua qualificação, títulos e se há formação constante. f) Pontos fortes: quais as características positivas que mais se destacam no sistema analisado.

g) Pontos fracos: quais os pontos que poderia ser melhorados.

Após o levantamento destes itens dos concorrentes, inicia-se o levantamento dos mesmos indicadores internamente, onde que esses levantamentos serão comparados e haverá a definição dos objetivos prioritários que a Instituição irá adotar em relação ao mercado em um determinado período de tempo. Após a determinação destes objetivos é iniciado a evolução para a próxima fase, a qual se fará por meio da divulgação e treinamento das equipes de trabalho para o estabelecimento do plano estratégico institucional.

Uma vez feito o alinhamento estratégico institucional, inicia-se a implantação das melhores práticas a partir dos benchmarks, sendo que, poderá ocorrer o acompanhamento constante sobre as modificações através do um processo avaliativo. Para a construção deste índice avaliativo poderá ser usado o AVA, no qual através de enquetes e questionários farão levantamentos sobre a satisfação do usuário, e coletas dados também sobre o seu desempenho e o índice de concluintes de cada curso, com o cruzamento destes dados poderá resultar no mapeamento das implementações e consequentemente a criação de relatórios para tomada de decisão para demais decisões.

Com 0 uso da boa prática do benchmarking, toda a IES poderá ser beneficiada, pois através da possível minimização dos erros devidos ao uso das comparações com práticas que já deram certo e o aprendizado com suas implementações, os gestores terão uma maior probabilidade de estipular metas eficazes para o futuro da Instituição e consequentemente aumentar seu diferencial competitivo. 


\section{CONCLUSÃO}

Este artigo procurou apresentar a TI como plataforma viabilizadora do sistema EAD, porém sob uma sucinta ótica logística, a intenção intrínseca foi de evidenciar a apropriação das "boas práticas" usadas na gestão da logística e cadeia de suprimentos, como possíveis formas de aprimoramento e fortalecimento dos processos para o modelo EAD. É ainda interessante salientar que, somente o aproveitamento destas teorias de logística sem a atualização da recíproca infraestrutura de $\mathrm{TI}$ levaria ao um processo ineficaz, como que em contrapartida, somente o investimento em infraestrutura de tecnológica sem o mínimo de visão das boas práticas, poderia remeter a oneração, desperdício de tempo e falta de qualidade, portanto é notável que $\mathrm{o}$ uso equilibrado dos esquemas logísticos aplicados a uma condizente infraestrutura de $\mathrm{TI}$ promoveria a otimização e padronização dos processos, elevando de forma considerável a vantagem competitiva para Organização. Com a exposição da aplicação das teorias dos princípios dos "4Rs" e do benchmarking no EAD, foi possível explicitar a sistematização e evolução desse processo qualitativo, onde que não somente seria possível implementar, mas sim agregar valor a toda cadeia e produtos.

Desta forma, através de um olhar sistêmico, ficou exposto que o ponto de maior expressão na incorporação destas boas práticas logísticas é a valorização das relações, tanto as tecnológicas, quanto mais ainda, as humanas, onde que, o maior desafio neste modelo demonstrado, é atingir a minimização dos autointeresses individuais e a maximização dos benefícios coletivos.

\section{REFERÊNCIAS}

ALMEIDA, M.E.B. Educação a distância na internet: abordagens e contribuições dos ambientes digitais de aprendizagem. 2003. Disponível
<http://www.scielo.br/scielo.php?pid=S1517-

$97022003000200010 \&$ script $=$ sci_arttext $>$. Acesso em: 14 jul. 2012.

BARROS, R.M. Um estudo sobre o poder das metáforas e dos recursos multimídia no processo de ensino e aprendizagem de cálculo diferencial e integral. 2008. 142f. Tese (Doutorado em Engenharia Elétrica) - Faculdade de Engenharia Elétrica e Computação, Universidade Estadual de Campinas, Campinas.

BRASIL. Decreto n. 6.603, de 12 dezembro de 2007. Dispõe sobre o exercício das funções de regulação, supervisão e avaliação de instituições de educação superior e cursos superiores de graduação e sequenciais no sistema federal de ensino. Diário da União, Brasília, DF, $13 \mathrm{dez}$. $2007 . \quad$ Disponível em: <http://www.planalto.gov.br/ccivil_03/_Ato20072010/2007/decreto/D6303.htm>. Acesso em: 14 set. 2012.

BRASIL. Decreto n. -5.622 , de 19 dezembro de 2005. Dispõe sobre a caracterização do ensino a distância. Diário da União, Brasília, DF, 20 dez. $2005 . \quad$ Disponível em: $<$ http://www.planalto.gov.br/ccivel03/ato20042006/2005/decreto/d5622.html>. Acesso em 15 jul. 2012.

CARVALHO, J.M.C. Logística. 3. ed. Lisboa: Edições Silabo, 2002.

CHRISTOPHER, M. Logística e gerenciamento da cadeia de suprimentos: criando redes que agregam valor. 2. ed. São Paulo: Cengage Learning, 2009.

GATES, B. A estrada do futuro. 1. ed. São Paulo: Cia das Letras, 1995.

MORAN, J.M. Avaliação do ensino superior a distância no Brasil. 2007. Disponível em: <http://www.eca.usp.br/prof/moran/avaliacao.htm. > Acesso em: 13 jul. 2012.

RELATÓRIO DO COMITÊ TEMÁTICO BENCHMARKING FNQ. São Paulo: [s.n.], 2005. $125 p$.

WEISS, D. Definição dos componentes necessários para a implantação de uma infraestrutura de TI para viabilizar uma plataforma EAD numa empresa de software e serviços. 2009. 81f. Trabalho de Conclusão de Curso (Bacharel em Administração) - Escola de Administração, Departamento de Ciências Administrativas, Federal do Rio Grande do Sul. Porto Alegre. 